Imalat Teknolojileri ve Uygulamalart

Cilt: 2, No: 3, 2021 (20-33)

Araștırma Makalesi

e-ISSN: 2717-7475

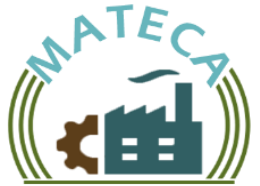

Manufacturing Technologies and Applications

Vol: 2, Issue: 3, 2021 (20-33)

Research Article

e-ISSN: 2717-7475

\title{
GG25 Dökme Demirin Frezelenmesinde Kesme Parametrelerinin Kesme Sıcaklığı Üzerine Etkisi ve Optimizasyonu
}

\author{
Raşit DÜZCE ${ }^{1}$ iD, Gürcan SAMTAȘ ${ }^{2, *}$ \\ ${ }^{I}$ Düzce Üniversitesi, Lisansüstü Ĕ̆itim Enstitüsü, Imalat Mühendisliği Bölümü, Düzce, Türkiye \\ ${ }^{2}$ Düzce Üniversitesi, Mühendislik Fakültesi, Düzce, Türkiye
}

\begin{tabular}{l} 
MAKALE BíLGíS \\
Alınma: 04.11.2021 \\
Kabul: 29.11 .2021 \\
\hline Anahtar Kelimeler: \\
GG25 \\
Yüzey frezeleme \\
Optimizasyon \\
Kesme sicaklığ \\
Taguchi
\end{tabular}

\section{ÖZET}

GG25 en yaygın olarak kullanılan dökme demir alaşımıdır. Bu malzeme, yüksek sağlamlık ve aşınma direncine sahiptir ve ek ssıl işleme ihtiyaç duymaz. Bu nedenle üretim maliyetleri düşüktür. Ağırlıklı olarak perlitik yapıya sahip lamelli bir dökme demirdir. Sertlikleri 230 Brinell'e kadar çıkabilmektedir. Bu nedenle özellikle delme ve frezeleme işlemleri zordur. $\mathrm{Bu}$ çalışmada özel olarak döktürülmüş GG25 numunelerine yüzey frezeleme işlemi gerçekleştirilmiştir. Yüzey frezeleme işlemi için üç farklı kaplamaya sahip kesici uç (TiAlN kaplamalı, TiN-TiCN-Al $\mathrm{O}_{3}$ kaplamalı ve AlTiN kaplamalı), üç farklı kesme hızı $(150,200$ ve $250 \mathrm{~m} / \mathrm{dak})$, üç farklı ilerleme $(0.10,0.25$ ve $0.35 \mathrm{~mm} /$ diş $)$ ve üç farklı kesme derinliği $(0.5,1$ ve $1.5 \mathrm{~mm})$ kesme parametresi olarak kullanılmıştır. Deneysel tasarım için Taguchi L27 $\left(3^{4}\right)$ ortogonal dizisi seçilmiş ve 27 deney gerçekleştirilmiş, kesme parametreleri Taguchi metodu ile optimize edilmiştir.. Her bir deney esnasında kesme bölgesinden termal kamera ile sicaklık ölçümleri yapılmıştır. Deneysel sonuçlar Varyans analizi ve üç boyutlu grafikler ile değerlendirilmiştir. Optimizayon sonucunda minimum sıcaklık için optimum parametreler, TiN-TiCN- $\mathrm{Al}_{2} \mathrm{O}_{3}$ kaplamalı kesici uç, $200 \mathrm{~m} /$ dak kesme hızı, $0.25 \mathrm{~mm} /$ diş ilerleme oranı ve $0.5 \mathrm{~mm}$ kesme derinliğidir. Varyans analizi değerlendirildiğinde sıcaklığa etki eden et etkili faktör kesme derinliği olmuştur. Taguchi optimize parametreler ve üç boyutlu grafikler değerlendirildiğinde, minimum sıcaklık için en uygun kaplama türü TiN-TiCN- $\mathrm{Al}_{2} \mathrm{O}_{3}$ kaplamalı kesici uç olduğu görülmüştür.

\section{Effect of Cutting Parameters on Cutting Temperature and Optimization in Milling of GG25 Cast Iron}

\section{ARTICLE INFO}

Received: 04.11 .2021

Accepted: 29.11 .2021

\section{Keywords:}

GG25

Face milling

Optimization

Cutting temperature

Taguchi

\begin{abstract}
GG25 is the most widely used cast iron alloy. This material has high strength and wear resistance, and does not require additional heat treatment. Therefore, production costs are low. It is a lamellar cast iron with a predominantly pearlitic structure. Their rigidity can go up to 230 Brinell. Therefore, drilling and milling operations are particularly difficult. In this study, face milling was performed on specially cast GG25 samples. For face milling, a cutting insert with three different coating (TiAlN coated, TiN-TiCN- $\mathrm{Al}_{2} \mathrm{O}_{3}$ coated, and AlTiN coated), three different cutting speeds (150, 200 and $250 \mathrm{~m} / \mathrm{min})$, three different penetration rates $(0.10,0.25$ and $0.35 \mathrm{~mm} /$ tooth $)$, and three different cutting depths $(0.5,1$ and $1.5 \mathrm{~mm})$ were used as cutting parameters. Taguchi L27 (34) orthogonal sequence was selected for experimental design, and 27 experiments were performed, and the cutting parameters were optimized by the Taguchi method. During each experiment, temperature measurements were taken on the cutting zone with a thermal camera. Experimental results were evaluated with analysis of variance and three-dimensional graphics. Optimum parameters regarding minimum temperature at the end of optimization were $\mathrm{TiN}-\mathrm{TiCN}-\mathrm{Al}_{2} \mathrm{O}_{3}$ coated cutting insert, cutting speed of $200 \mathrm{~m} / \mathrm{min}, 0.25 \mathrm{~mm} / \mathrm{head}$ penetration rate, and $0.5 \mathrm{~mm}$ cutting depth. When the analysis of variance was evaluated, the most effective factor affecting the temperature was cutting depth. When the Taguchi optimized parameters and three-dimensional graphics were evaluated, it was seen that the most suitable coating type for minimum temperature is $\mathrm{TiN}-\mathrm{TiCN}-\mathrm{Al}_{2} \mathrm{O}_{3}$ coated cutting insert.
\end{abstract}




\section{GİRIŞ (INTRODUCTION)}

Dökme demirler; sertlik, aşınma direnci, işlenebilirlik, korozyon direnci ve mukavemet gibi mekanik özelliklerinin yanı sıra daha kolay üretilebilir ve ekonomik olmalarından ötürü yaygın olarak kullanılan mühendislik malzemeleridir [1]. Dökme demirlerin işlenmesi yani talaşlı imalatı, dökümün tipine ve mikro yapısına bağlıdır. Beyaz dökme demirin talaşlı imalatı oldukça zor iken, ferritik dökümün ise, diğer dökme demirlere oranla daha kolaydır. Küresel grafitli dökme demir, vermüküler grafitli dökme demir, alaşımlı ve temper dökme demirlerin işlenebilirlikleri ise beyaz ve ferritik döküm arasındadır [2].

Talaşlı imalatta kullanılan kesici takımlarda oluşan deformasyonlar; işlenen malzemenin yüzey kalitesini olumsuz yönde etkilemektedir. $\mathrm{Bu}$ olumsuzluklardan en önemlisi takım ömrünün azalmasıdır. Kesici takımların ömrünün azalması, kesici takım maliyetlerini, diğer bir deyişle üretim maliyetlerini etkileyen en önemli faktörlerden birisidir. Dolayısıyla takım ömrünü etkileyen parametrelerin bilinmesi, bu parametrelerin kontrol altına alınabilecek tedbirlerin geliştirilmesi büyük önem taşımaktadır [3].

Bir malzemenin iyi mekanik özelliklere sahip olması, o malzemeyi diğer malzemelerden ayıran en önemli etkenlerden bir tanesidir. Ayrıca, malzemenin talaşlı imalatı da mekanik özellik kadar ayrı bir önem taşımaktadır. Mühendislik malzemelerinin talaşlı imalatlarının iyileştirilmesi, imalat esnasında maliyeti düşüreceği için, endüstriyel anlamda önemli bir parametredir. Bu nedenle, literatürde talaşlı imalat ile ilgili değişik çalışmalara rastlamak mümkündür. Literatür değerlendirildiğinde bazı çalışmalarda, küresel grafitli dökme demir ve östemperlenmiş küresel grafitli dökme demirlere katılan alaşım elementlerinin, mikroyapı, mekanik özellikleri, kesme kuvveti ve yüzey pürüzlülükleri üzerinde büyük etkilerinin olduğu belirtilmiştir [4, 5]. Yine bazı çalışmalarda, küresel grafitli dökme demir ve östemperlenmiş küresel grafitli dökme demirlerin talaşlı imalatında, düşük östemperleme sıcaklığının, kesme kuvvetlerini artırırken yüzey pürüzlülüğü değerlerini düşürdüğü, hızın artırılmasının ise, kesme sürecinde oluşan titreşimi azalttığ 1 belirtilmiştir [6,7]. Ayrıca literatürde, östemperlenmiş küresel grafitli dökme demirlerin abrasif aşınma davranışına, östemperleme işleminde soğutmanın etkisini ve östemperleme sıcaklığının ve süresinin talaşlı imalat üzerine etkisini araştıran, değişik çalışmalara da rastlanmaktadır [8-10]. Moncoda vd. östemperlenmiş dökme demirlerin tornalanmasında işlenebilirliği etkileyen parametreleri araştırmışlardır [11]. Dökme demirlerin işlenebilirliğinde kesici takımlarda ortaya çıkan aşınma tipleri abreziv, adeziv ve difüzyon aşınmalarıdır. Dökme demir işlemede aranan kesici takım özellikleri yüksek sertlik ve kimyasal kararlılıktır. Sinterlenmiş karbürlerin yanı sıra seramik kesici takımlar da dökme demir işlemede kullanılır [12]. Marwanga vd., tornalama işleminde; işleme sırasında dökme demirlerin mikro yapısındaki değişiklikleri incelemişlerdir [13]. Ahmet vd. yaptıkları çalışmada, dört farklı lamel grafitli dökme demirlerin tornalanmasında kalem ile parça arasında meydana gelen gerilme, işleme şartları ve malzeme yapısının etkisini araştırmışlardır. Çalışmalarında, gerilim farkı artışının en büyük etkeni, toplam kesitteki grafit miktarı artışından kaynaklandığını tespit etmişlerdir [14]. Kaçal vd., GGG70 sfero dökme demirin frezelenmesinde kesici takım aşınması ve yüzey pürüzlülüğünü araştırmışlardır. Deney sonuçlarına göre ilerleme değerinin artmasıyla yüzey pürüzlülüğünün de arttığı görülmüştür [15]. Kahraman vd. yaptıkları çalışmada, vermiküler grafitli dökme demirlerin frezelenmesinde östemperleme sıcaklığ 1 ve süresinin yüzey pürüzlülügüne etkisini araştırmışlardır. Çalışmalarında östemperleme 1sıl işleminin malzemelerin yüzey kalitesini iyileştirdiğini gözlemlemişlerdir [16]. Çakıroğlu ve Uzun yaptıkları çalışmada, vermiküler grafitli dökme demirlerin frezelenmesinde oluşan kesme kuvvetinin ve iş parçası yüzey pürüzlülügünün yapay sinir ağları ile modellenmesini gerçekleştirmişlerdir. Elde edilen matematiksel model sonucu tahmin edilen değerler ile deney sonuçları arasında uyum olduğu görülmüştür [17]. Aşkun vd. yaptıkları çalışmada, Ni ve $\mathrm{Cu}$ ile alaşımlandırılmış küresel grafitli dökme demirlerin işlenebilirliğini kesme kuvvetleri ve yüzey kaliteleri açısından değerlendirmişlerdir [18]. Avishan vd., alaşımlı östemperlenmiş dökme demirin işlenebilirliği üzerine kesme derinliklerinin etkisi incelemişlerdir. Çalışmalarının sonucunda kesme derinliğinin azaltılmasının işlenebilirliği iyileştirmeyeceğini ifade etmişlerdir [19]. Da Silva vd. yaptıkları çalışmada, yüksek kromlu beyaz dökme demir alaşımının, tornalanmasında işlenebilirlik 
kabiliyetini incelemişlerdir. Çalışmalarını kuru ve ıslak soğutma şartlarında gerçekleştirerek, kübik bor nitrür kesici takımlar kullanmışlardır. Çalışmada kullandıkları kesme sıvısının daha düşük pürüzlülük değerleri, iyileştirilmiş takım ömrü ve takım aşınma performansına olumlu etkileri olduğunu vurgulamışlardır [20]. Eraslan vd., yaptıkları çalışmada, benzer özelliklere sahip G18NiMoCr3-6+QT1 dökme çelik ve 1050-6 östemperlenmiş sfero dökümün frezeleme işlemleri sırasında işlenebilirlik özelliklerini incelemişlerdir. Deneyler, kuru, geleneksel kesme sıvısı ve minimum miktarda yağlama koşulları altında TiALN kaplamalı kesici uçlarla gerçekleştirilmiştir. Her bir deney için kesme kuvvetleri, takım aşınması, ortalama yüzey pürüzlülüğü ve mikrosertlik değişimlerini her iki malzeme için analiz etmişlerdir. Her iki malzeme için kuru şartlarda işlemenin daha elverişli olduğu sonucuna varmışlardır [21]. Lu vd., Sıkıştırılmış grafit dökme demirin işlenmesi sonrası elde edilen yüzey pürüzlülüğünü tahmin etmek için istatistiksel yöntemler kullanmışlardır. Analiz sonrası, kesme hızı ve ilerleme oranının yüzey pürüzlülüğüne önemli düzeyde etkilediğini, kesme derinliğinin ise pürüzlülük üzerine çok az etkisi olduğu sonucuna varmışlardır [22]. Da Silva vd., grafitli dökme demirin frezeleme işleminde işlenebilirliğini araştırmışlardır. Çalışmalarında grafitli dökme demirin; normal, rafine ve rafine grafitli molibden ilaveli olarak üç farklı türünü kullanmışlardır. Bu malzemenin işlenebilirliği, takım ömrü ve aşınma mekanizmaları, malzeme yüzey kalitesi ve elektrik akımı tüketimi açısından değerlendirilmiştir. Elde edilen sonuçlarda; takım ömrü, yüzey kalitesi ve elektrik akımı tüketimi açısından en önemli kesme parametrelerinin, takım ömrü, ilerleme oranı ve iş parçası malzemesi olduğunu vurgulamışlardır [23]. Çakıroğlu ve Uzun, vermüküler grafitli dökme demir numunelerine farklı östemperleme işlemi uygulayarak bu numunelere yüksek ilerlemede frezeleme deneyleri gerçekleştirmişlerdir. Deneylerde kesme kuvvetleri ile pürüzlülük ölçümü yapmışlardır. Deneylerin sonucunda elde edilen deneysel veriler kullanılarak Yapay Sinir Ağları yöntemiyle matematiksel model geliştirmişlerdir [17].

Literatür değerlendirildiğinde bu çalışmanın, kullanılan frezeleme yöntemi, kesici uçlar ve kesme sıcaklığının değerlendirilmesi ve Taguchi metodunun kullanılması açısından özgün bir değer taşıdığ1 görülmüştür. Bu çalışmada GG25 dökme demirin frezelenmesinde kesme parametrelerinin kesme sıcaklığı üzerine etkileri araştırılmış ve kesme parametreleri Taguchi metodu kullanılarak optimize edilmiştir. Çalışmada L27 $\left(3^{4}\right)$ Taguchi ortogonal dizisi kullanılarak deney sayısı azaltılmıştır. Deneysel sonuçlar varyans analizi ve üç boyutlu grafikler ile değerlendirilmiştir. Ayrıca Taguchi tahmin değeri ile deneysel sonuçlar karşılaştırılmıştır.

\section{MATERYAL VE METOT (MATERIAL AND METHOD)}

ISO 8688-1 standardına göre frezelenecek olan deney numunesi için tavsiye edilen ölçüler, kullanılan takım tutucu çapının en az 3 katı kadar boy ve 0.6 katı kadar kesme genişliği ölçülerinde olmasıdır [24]. Bu durum dikkate alınarak frezeleme deneylerinde GG25 dökme demir kullanılmıştır. GG25 Dökme demire ait teknik özellikler Tablo 1 ve Tablo 2'de gösterilmiştir.

Tablo 1. GG25 dökme demire ait bileşenler (Components of GG25 cast iron) [25]

\begin{tabular}{cccccc}
\hline $\mathbf{C}$ & $\mathbf{F e}$ & $\mathbf{M n}$ & $\mathbf{P}$ & $\mathbf{S i}$ & $\mathbf{S}$ \\
\hline$\% 2.95-3.45$ & $\% 92.63-94.26$ & $\% 0.55-0.75$ & $\% 0.10-0.20$ & $\% 2.1-2.9$ & $\% 0.040-0.070$ \\
\hline
\end{tabular}

Tablo 2. GG25 dökme demire ait mekanik özellikler (Mechanical properties of GG25 cast iron) [25]

\begin{tabular}{ccc}
\hline Yoğunluk & Sertlik Brinell & Çekme Dayanımı \\
\hline $7.30 \mathrm{~g} / \mathrm{cm}^{3}$ & 180 & $155 \mathrm{Mpa}$ \\
\hline
\end{tabular}

Deneylerde WIDIA (Germany) kesici takım firmasına ait TN6525 kodlu TiALN kaplanmış, TN7535 kodlu TiN-TiCN-Al $\mathrm{O}_{3}$ kaplanmış ve WS30PM kodlu ALTiN (çok katmanlı) kaplanmış 4 
kesme kenarına sahip kesici uçlar kullanılmıştır. Ayrıca kullanılan uçlara uygun 3 ağızlı takım tutucu, özel olarak üretilmiş olup muadil olarak temin edilmiştir (Şekil 1).
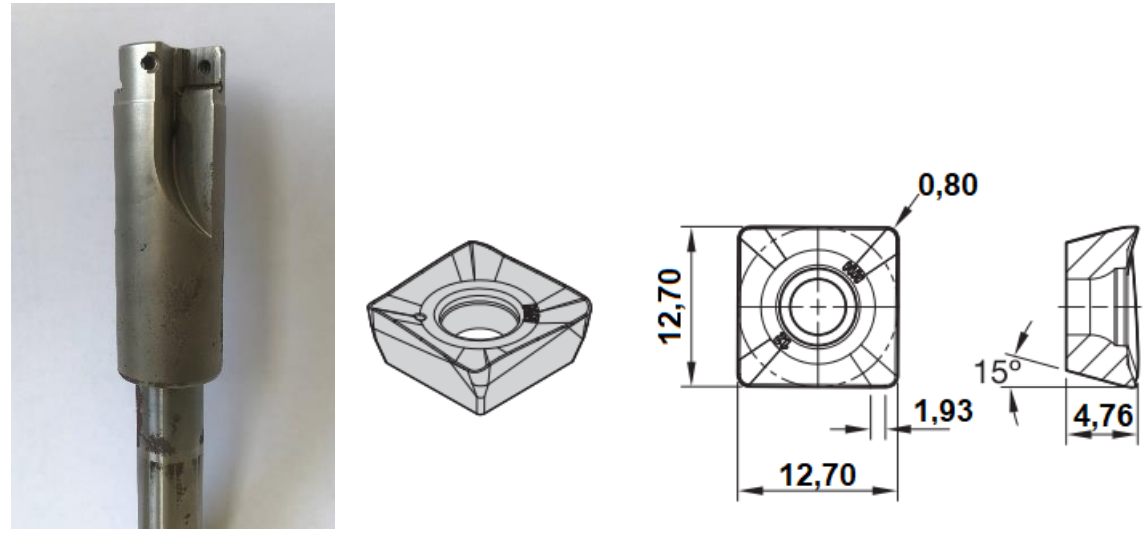

Şekil 1. Kullanılan takım tutucu ve kesici uç (Used tool holder and cutting insert)

Frezeleme işlemlerinde DELTA SEIKI 1050A üç eksenli dikey freze tezgâhı kullanılmıştır. Deneyler soğutma sıvısı kullanılmadan kuru ortamda yürütülmüştür. Her bir deney için kesici takım talaş kaldırmaya başladıktan sonra, işleme boyunun yaklaşık orta noktasından Fluke TiS20 model termal kamera ile sıcaklık ölçümleri yapılmıştır. Termal kameraya ait bilgisayar programı, çekilen termal görüntüleri işleyerek bu sıcaklıkların minimum, maksimum ve ortalama değerleri göstermektedir. $\mathrm{Bu}$ çalışmada kesme bölgesinden alınan termal görüntüler incelenerek, her bir deney için maksimum sıcaklık dikkate alınmıştır. Kullanılan termal kamera $-20{ }^{\circ} \mathrm{C}$ ile $350{ }^{\circ} \mathrm{C}$ arası ölçüm yapabilen, dedektör çözünürlüğü 120x90, görüş alanı $35.7^{\circ}$ x $26.8^{\circ}$ ve $9 \mathrm{~Hz}$ kare hızına sahiptir. Kullanılan malzemenin emissivity (yayınım) değeri 0.82 olarak alınmıştır. Deneysel kurulum ve çalışmayı gösteren şema Şekil 2'de gösterilmiştir.

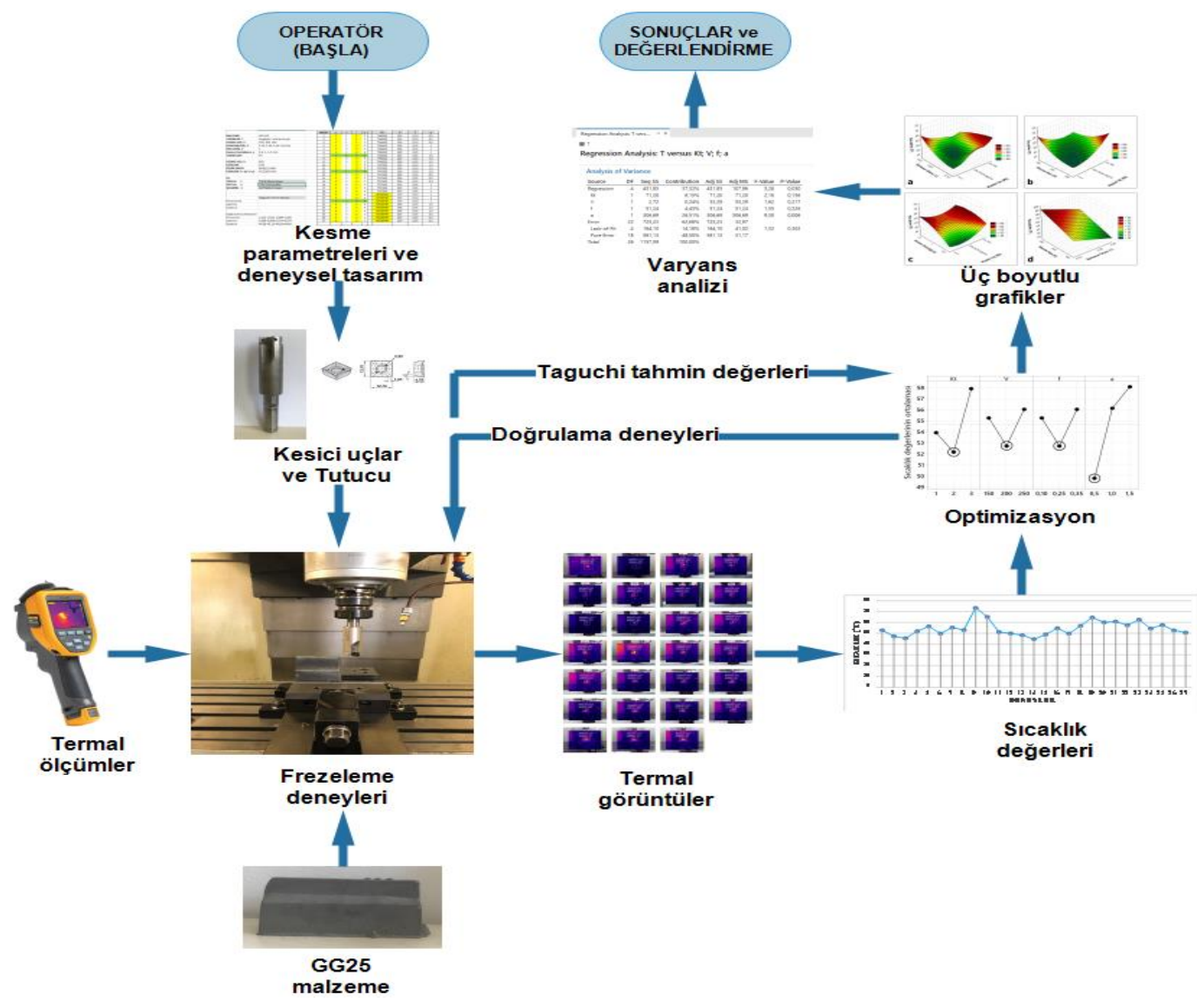

Şekil 2. Deneysel kurulumun akış şeması (The flowchart of experimental setup) 


\subsection{Taguchi Metodu (Taguchi method)}

İlk olarak 60’lı yıllarda Genuchi Taguchi tarafından önerilen bir metot olup, endüstriyel ürün kalitesinin iyileştirilmesinde kullanılan yaygın bir tekniktir. Taguchi metodu sayesinde deney öncesi yapılacak ayrıntılı analiz ve değerlendirmelerle gereken deney sayısı önemli şekilde azaltmak mümkündür. Taguchi metodu bir deney tasarım tekniği olmanın ötesinde parametre optimizasyonu ve minimum deney sayısıyla maksimum verimlilik sunan son derece faydalı bir tekniktir [26, 27].

Bu çalışmada kullanılan Taguchi tekniği şu adımları içermektedir: (1) Faktörlerin belirlenmesi; (2) Her bir faktöre ait seviyelerin belirlenerek uygun ortogonal dizinin seçilmesi; (3) Seçilen ortogonal matrise faktörlerin atanması ve deneylerin yapılması; (4) Verilerin analizi ve faktörlerin optimal seviyelerin belirlenmesi; (5) Doğrulama deneylerinin yapılarak güven aralığının elde edilmesi; (6) Taguchi tahmin değerlerinin hesaplanması ve deneysel sonuçlarla karşılaştırılması. Taguchi metodu, arzu edilen değerlerden performanslarının karakteristik sapmalarının ölçülmesi için bir kayıp fonksiyon kullanır. Kayıp fonksiyon değerleri ayrıca, bir sinyal gürültü oranına (S/N) dönüştürülmektedir. Genel olarak $\mathrm{S} / \mathrm{N}$ oranı analizinde, en küçük en iyi, en yüksek en iyi ve nominal daha iyi olmak üzere üç farklı kalite karakteristikleri vardır. İşlem parametrelerinin her bir seviyesi için sinyal oranı, S/N analizi temel alınarak hesaplanmaktadır.

\section{SONUÇLARIN DEĞERLENDİRILMESİ (EVALUATION OF RESULTS)}

Deneysel tasarım için Taguchi L27 $\left(3^{4}\right)$ ortogonal dizisi kullanılmış, tam tasarım 81 deney yerine sadece 27 deney yapılmıştır. Taguchi metodu ile yapılan analiz ve değerlendirmelerde deney sayısı önemli derecede azaltmak mümkündür. Taguchi metodu, kalite özelliklerini belirlemede bazı fonksiyonlar kullanmaktadır. Bu çalışmada kesme bölgesi sıcaklık ölçümlerinde en küçük değer arzu edildiği için Taguchi "En küçük en iyi” fonksiyonu kullanılmıştır. Tablo 3'de seçilen kesme parametreleri ve bu parametrelerin seviyeleri verilmiştir. Kesme parametrelerinin belirlenmesinde malzeme ve kesici takım kataloğu dikkate alınmıştır [28, 29]. L27 ortogonal dizisi dikkate alınarak oluşturulan deneysel tasarım, deneysel sonuçlar ve deneysel sonuçlara göre hesaplanan sinyal gürültü $(\mathrm{S} / \mathrm{N})$ oranları Tablo 4'de verilmiştir.

Tablo 3. Kesme parametreleri (Cutting parameters)

\begin{tabular}{cccc}
\hline Parametreler & Seviye 1 & Seviye 2 & Seviye 3 \\
\hline $\begin{array}{c}\text { Kesici uçlar } \\
(\mathrm{Kt})\end{array}$ & TiALN & TiN-TiCN-Al $\mathrm{O}_{3}$ & ALTiN \\
\hline $\begin{array}{c}\text { Kesme hız1 } \\
(\mathrm{V}, \mathrm{m} / \text { dak })\end{array}$ & 150 & 200 & 250 \\
\hline $\begin{array}{c}\text { İlerleme oran } \\
(\mathrm{f}, \mathrm{mm} / \text { diş })\end{array}$ & 0.10 & 0.25 & 0.35 \\
\hline $\begin{array}{c}\text { Kesme derinliği } \\
(\mathrm{a}, \mathrm{mm})\end{array}$ & 0.5 & 1 & 1.5 \\
\hline
\end{tabular}

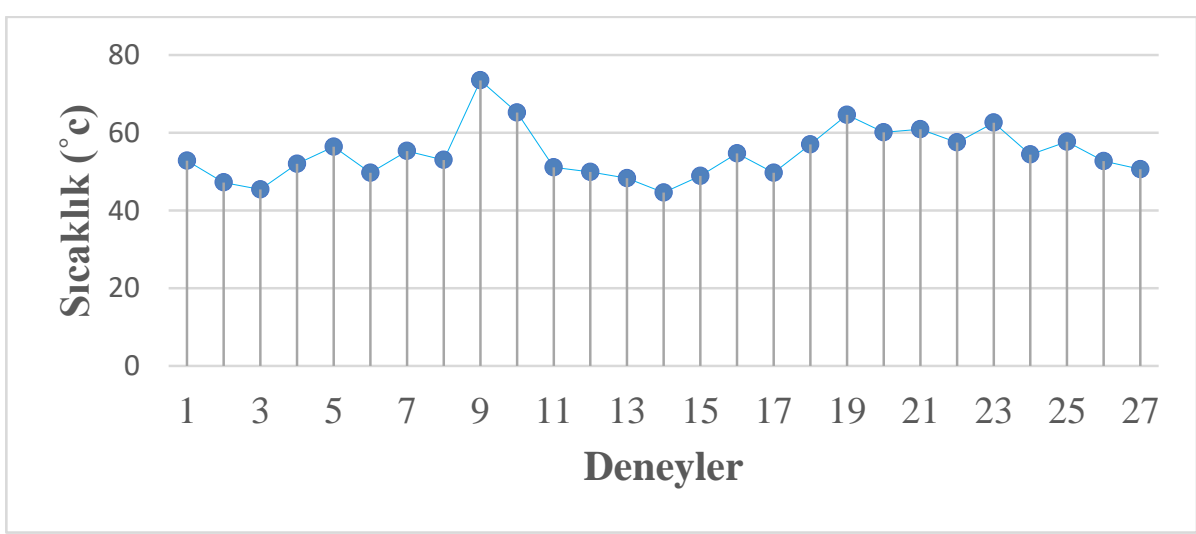

Şekil 3. Deneylerden elde edilen sıcaklık değerleri (Temperature values obtained from experiments) 
Deneylerden elde edilen sıcaklık değerleri ve bu değerlere ait sinyal gürültü oranları dikkate alındığında, sıcaklık sonuçlarının ortalama değeri $54.659{ }^{\circ} \mathrm{C}$ ve sıcaklık için ortalama $\mathrm{S} / \mathrm{N}$ oranı da 34.694 dB olarak hesaplanmıştır. Şekil 3'de sıcaklık değerlerine ait grafik verilmiştir.

Tablo 4. Deneysel tasarım ve ölçülen sıcaklık değerleri (Experimental design and measured temperature values)

\begin{tabular}{|c|c|c|c|c|c|c|}
\hline \multirow{3}{*}{ 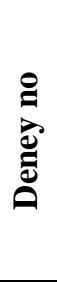 } & \multicolumn{4}{|c|}{ Kesme parametreleri } & \multicolumn{2}{|c|}{$\begin{array}{c}\text { Deneysel Sonuçlar ve } \\
\text { S/N oranları }\end{array}$} \\
\hline & $\mathbf{A}$ & B & $\mathbf{C}$ & D & & \\
\hline & $\begin{array}{l}\text { Kesici uçlar } \\
\text { (Kt) }\end{array}$ & $\begin{array}{c}\text { Kesme } \\
\text { hızı } \\
(\mathrm{V})\end{array}$ & $\begin{array}{c}\text { İlerleme } \\
\text { oranı } \\
\text { (f) } \\
\end{array}$ & $\begin{array}{c}\text { Kesme } \\
\text { derinliği } \\
\text { (a) } \\
\end{array}$ & $\begin{array}{c}\text { Sicaklık } \\
\left(\mathrm{T},{ }^{\circ} \mathrm{C}\right)\end{array}$ & $\begin{array}{l}\mathbf{S} / \mathbf{N}_{\mathbf{T}} \\
(\mathbf{d B})\end{array}$ \\
\hline 1 & TiALN & 150 & 0.10 & 0.5 & 52.8 & -34.453 \\
\hline 2 & TiALN & 150 & 0.10 & 0.5 & 47.2 & -33.479 \\
\hline 3 & TiALN & 150 & 0.10 & 0.5 & 45.4 & -33.141 \\
\hline 4 & TiALN & 200 & 0.25 & 1 & 52 & -34.320 \\
\hline 5 & TiALN & 200 & 0.25 & 1 & 56.4 & -35.026 \\
\hline 6 & TiALN & 200 & 0.25 & 1 & 49.7 & -33.927 \\
\hline 7 & TiALN & 250 & 0.35 & 1.5 & 55.3 & -34.855 \\
\hline 8 & TiALN & 250 & 0.35 & 1.5 & 53 & -34.486 \\
\hline 9 & TiALN & 250 & 0.35 & 1.5 & 73.5 & -37.326 \\
\hline 10 & TiN-TiCN-Al ${ }_{2} \mathrm{O}_{3}$ & 150 & 0.10 & 1.5 & 65.2 & -36.285 \\
\hline 11 & TiN-TiCN-Al ${ }_{2} \mathrm{O}_{3}$ & 150 & 0.10 & 1.5 & 51.1 & -34.168 \\
\hline 12 & TiN-TiCN-Al ${ }_{2} \mathrm{O}_{3}$ & 150 & 0.10 & 1.5 & 49.9 & -33.962 \\
\hline 13 & TiN-TiCN-Al ${ }_{2} \mathrm{O}_{3}$ & 200 & 0.25 & 0.5 & 48.3 & -33.679 \\
\hline 14 & TiN-TiCN-Al ${ }_{2} \mathrm{O}_{3}$ & 200 & 0.25 & 0.5 & 44.6 & -32.987 \\
\hline 15 & TiN-TiCN-Al ${ }_{2} \mathrm{O}_{3}$ & 200 & 0.25 & 0.5 & 48.9 & -33.786 \\
\hline 16 & TiN-TiCN-Al ${ }_{2} \mathrm{O}_{3}$ & 250 & 0.35 & 1 & 54.7 & -34.760 \\
\hline 17 & TiN-TiCN-Al ${ }_{2} \mathrm{O}_{3}$ & 250 & 0.35 & 1 & 49.7 & -33.927 \\
\hline 18 & TiN-TiCN-Al $\mathrm{O}_{3}$ & 250 & 0.35 & 1 & 57 & -35.117 \\
\hline 19 & ALTiN & 150 & 0.10 & 1 & 64.6 & -36.205 \\
\hline 20 & ALTiN & 150 & 0.10 & 1 & 60.1 & -35.577 \\
\hline 21 & ALTiN & 150 & 0.10 & 1 & 60.9 & -35.692 \\
\hline 22 & ALTiN & 200 & 0.25 & 1.5 & 57.5 & -35.193 \\
\hline 23 & ALTiN & 200 & 0.25 & 1.5 & 62.6 & -35.931 \\
\hline 24 & ALTiN & 200 & 0.25 & 1.5 & 54.4 & -34.712 \\
\hline 25 & ALTiN & 250 & 0.35 & 0.5 & 57.7 & -35.224 \\
\hline 26 & ALTiN & 250 & 0.35 & 0.5 & 52.7 & -34.436 \\
\hline 27 & ALTiN & 250 & 0.35 & 0.5 & 50.6 & -34.083 \\
\hline
\end{tabular}

\subsection{Optimum Seviyelerin Belirlenmesi (Determining Optimum Levels)}

Tablo 5'de kesme parametreleri, bu çalışmada kullanılan ortogonal dizi dolayısıyla farklı seviyeler ve olası etkileri dikkate alınarak ayırt edilmiştir. Bu seviyeler deneysel çalışmada sıcaklık değerlerinin analizi için hesaplanan sinyal gürültü oranlarının ortalama değerlerini göstermektedir. $\mathrm{Bu}$ değerler, belirlenen optimum parametreler için tahmin değerleri hesaplamak için kullanılır.

Tablo 5. Her bir seviye için S/N oranları ortalamaları (Averages of S/N ratios for each level)

\begin{tabular}{lcccc}
\hline Kesme parametreleri & \multicolumn{3}{c}{ Seviyeler } & \multirow{2}{*}{ Mak-Min } \\
\cline { 2 - 4 } & Seviye 1 & Seviye 2 & Seviye 3 & \\
\hline A (Kesici uç, Kt) & -34.64 & -34.36 & -34.25 & 0.89 \\
\hline B (Kesme hızı, V) & -34.83 & -34.42 & -34.99 & 0.58 \\
\hline C (İlerleme oranı, f) & -34.83 & -34.42 & -34.99 & 0.58 \\
\hline D (Kesme derinliği, a) & -33.94 & -34.97 & -35.33 & 1.39 \\
\hline
\end{tabular}

Tablo 4'de mak-min (maksimum-minimum) değeri, her bir parametrenin ilgili seviyelerinin maksimum ortalaması ile minimum değerlerin ortalamasının arasındaki farktır. Taguchi metodunda 
önemli olan aşamalardan bir tanesi, optimum seviyeleri belirlemektir. Optimum seviyeler, seçilen ortogonal dizi tarafından oluşturulan kombinasyonlar, yani kesme parametrelerinin farklı seviyelerini değerlendirerek belirlenmektedir. Bu seviyeler, seviyelere ait etki grafiklerini çizmek için kullanılır (Şekil 4). Ana etki grafiğgi değerlendirilirken, bu çalışmada arzu edilen minimum sıcaklık olduğu için, sıcaklık değerleri için en düşük seviye, sıcaklık değerleri $\mathrm{S} / \mathrm{N}$ oranlarının ise en yüksek seviyeleri dikkate alınır.

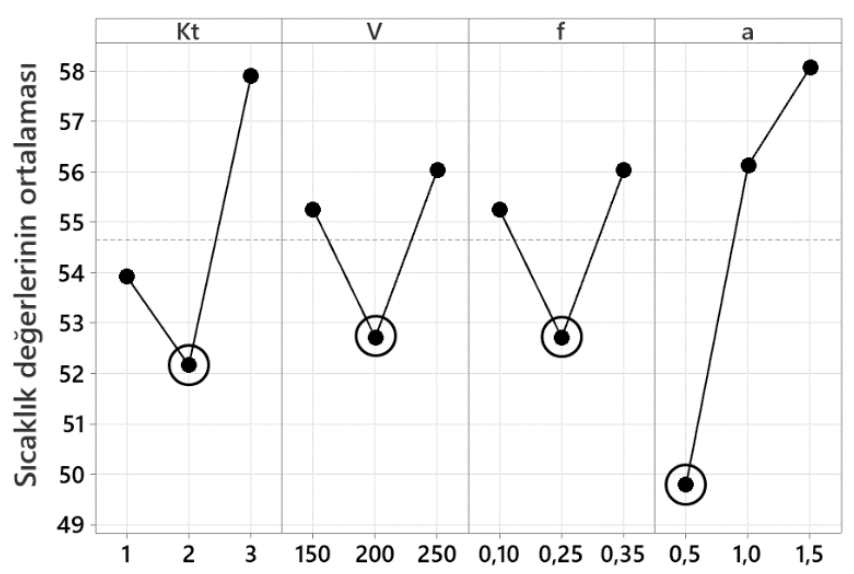

Şekil 4. Sıcaklık değerleri için ana etki grafiği (Main effect graph for temperature values)

Şekil 4'e göre minimum sıcaklık değerleri için deney parametrelerinin optimum kombinasyonu $\mathrm{A}_{2} \mathrm{~B}_{2} \mathrm{C}_{2} \mathrm{D}_{1}\left(\mathrm{~A}_{2}=\right.$ TiN-TiCN-Al ${ }_{2} \mathrm{O}_{3}$ kaplamalı kesici uç, $\mathrm{B}_{2}=200 \mathrm{~m} /$ dak kesme hızı, $\mathrm{C}_{2}=0,25$ $\mathrm{mm} /$ diş ilerleme oranı ve $\mathrm{D}_{1}=0.5 \mathrm{~mm}$ kesme derinliği) olarak belirlenmiştir.

\subsection{Kesme Parametrelerinin Varyans Analizi ile Değerlendirilmesi (Evaluation of Cutting Parameters by Analysis of Variance)}

Deney tasarımında kullanılan tüm kontrol faktörlerinin birbirlerini nasıl etkilediğini, bunun performans özellikleri üzerinde nasıl bir etkisi olduğunu ve performans özelliklerinde parametrelerin farklı seviyelerinde ne gibi değişiklikler olduğunu belirlemek için ve Taguchi güven aralıklarının belirlenmesinde varyans analizi kullanılmaktadır [30, 31]. Kesici takım, kesme hızı, ilerleme oranı ve kesme derinliğinin sıcaklık üzerine etkileri varyans analizi ile değerlendirilmiş, varyans analizi sonuçları Tablo 6'da gösterilmiştir.

Tablo 6. Deneysel sonuçlar için ANOVA sonuçları (ANOVA results for experimental results)

\begin{tabular}{lcccccc}
\hline Faktörler & $\begin{array}{c}\text { Serbestlik } \\
\text { derecesi } \\
\text { (DoF) }\end{array}$ & $\begin{array}{c}\text { Kareler } \\
\text { toplamı } \\
\text { (SS) }\end{array}$ & $\begin{array}{c}\text { Kareler } \\
\text { ortalaması } \\
(\mathbf{M S})\end{array}$ & F - Değeri & P-Değeri & $\begin{array}{c}\text { Faktör } \\
\text { etkisi } \\
(\%)\end{array}$ \\
\hline Kesici takım (Kt) & 1 & 71.20 & 71.20 & 2.16 & 0.156 & 6.15 \\
Kesme hizı (V) & 1 & 2.72 & 53.29 & 1.62 & 0.217 & 0.24 \\
İlerleme oranı (f) & 1 & 51.24 & 51.24 & 1.55 & 0.226 & 4.43 \\
Kesme derinliği (a) & 1 & 306.69 & 306.69 & 9.30 & 0.006 & 26.51 \\
Hata (e) & 22 & 725.23 & 32.97 & & & 62.68 \\
Toplam & 26 & 1157.09 & & & & 100 \\
\hline
\end{tabular}

Varyans analizi sonuçları değerlendirildiğinde sıcaklığa etki eden en etkili parametre \%26.51 ile kesme derinliği olmuştur. Bu parametreyi \% 6.15 ile kesici uç takip etmektedir. Talaş derinliğinin artması birim alana düşen sürtünmeyi arttıracağından sıcaklığın da artmasına neden olmaktadır. Dolayısıyla sıcaklık için varyans analizi sonuçları tutarlıdır denilebilir. 


\subsection{Doğrulama Deneyleri ve Taguchi Tahmin Değerlerinin Hesaplanması (Confirmation Experiments and Calculation of Taguchi Prediction Values)}

Taguchi metodunun son adımı olan doğrulama deneylerinin amacı, kalite özelliklerini analiz etmektir. Ayrıca optimizasyon sürecinin doğruluğunu test etmek için de doğrulama deneyleri kullanılır. Yani diğer bir deyişle doğrulama deneyleri, kesme parametrelerinin ve seviyelerinin belirlenen optimum kombinasyonu test etmek amaciyla yapılır. Kesme parametrelerinin bireysel etkileri dikkate alınarak sıcaklık için elde edilen optimum kombinasyona göre $\mathrm{A}_{2} \mathrm{~B}_{2} \mathrm{C}_{2} \mathrm{D}_{1}\left(\mathrm{~A}_{3}=\mathrm{TiN}\right.$ TiCN- $\mathrm{Al}_{2} \mathrm{O}_{3}$ kaplamalı kesici uç, $\mathrm{B}_{2}=200 \mathrm{~m} /$ dak kesme hızı, $\mathrm{C}_{2}=0.25 \mathrm{~mm} /$ diş ilerleme oranı ve $\mathrm{D}_{1}$ $=0.5 \mathrm{~mm}$ kesme derinliği) tahmin sicaklık değeri $\left(\mathrm{T}_{\mathrm{p}}\right)$ aşağıda verilen eşitliklerle hesaplanır [3234].

$\eta_{g T}=A_{2}+B_{2}+C_{2}+D_{1}-3 \eta_{\frac{S}{N}-T}$

$T_{p}=10^{-\eta_{g T} / 20}$

Eşitliklerde; $\mathrm{A}_{2} \mathrm{~B}_{2} \mathrm{C}_{2} \mathrm{D}_{1}$ faktörlerin optimum seviyelerine ait sinyal gürültü oranlarıdır (Tablo 5). Buna göre; $\mathrm{A}_{2}=-34.36, \mathrm{~B}_{2}=-34.42, \mathrm{C}_{2}=-34.42$ ve $\mathrm{D}_{1}=-33.94 \mathrm{~dB}$ olarak Tablo 5'den okunmuştur. $\eta_{\frac{S}{N}-T}$ sıcaklık değerlerinin $\mathrm{S} / \mathrm{N}$ oranları ortalamasıdır. $\eta_{g T}$ sıcaklık optimum seviyeleri için hesaplanan $\mathrm{S} / \mathrm{N}$ oranı, $T_{p}$, sicaklık için hesaplanan Taguchi tahmin değerleridir. Denklem 1 ve denklem 2 kullanılarak hesaplanan sıcaklık tahmin değeri $44.96{ }^{\circ} \mathrm{C}$ olarak bulunmuştur. Doğrulama deneylerinin sonucunu tahmin değerle karşılaştırılmasında ve kalite özelliğinin doğrulanmasında güven aralığı (CI) kullanılmaktadır. Güven aralığı maksimum ve minumum değer olup, hesaplanan değer tahmin değerleri ile karşılaştırılarak doğrulama deneylerinin doğruluğu test edilir. CI aşağıda verilen eşitlik ile hesaplanır [26-28].

$$
C I=\sqrt{F_{\alpha: 1, V e} x V_{e p} x\left(\frac{1}{n_{e f f}}+\frac{1}{r}\right)}
$$

Eş. 3'de $F_{\alpha: 1,}, v_{e}$ önem düzeyi $\alpha$ 'nın F oranı, $\alpha$ önem düzeyi, 1- $\alpha$ güven aralığg, $V_{e}$ varyans analizi sonuçlarına göre sıcaklığa ait hatanın serbestlik derecesidir. Tablo 6 incelendiğinde hatanın serbestlik derecesi 22 dir. Bu durumda \%95 güven seviyesine ait F tablosundan 1-22 değeri 4.30 olarak bulunmuştur. $V_{e p}$ yine varyans analizi sonuçlarına göre hatanın varyansı, $r$ doğrulama deney sayısı ve $n_{\text {eff }}$ etkin ölçülen sonuçların sayısıdır $[34,35]$.

$$
n_{e f f}=\frac{N}{1+V_{t}}
$$

Eş. 4'de $N$, toplam deney sayısını (27), $V_{t}$ Tablo 6 dikkate alınarak ortalamanın hesaplandığı kesme parametrelerine ait toplam serbestlik derecesini (4) ifade etmektedir. Bu durumda $n_{\text {eff, }} 5.4$ olarak hesaplanmıştır. Bu çalışmada, sıcaklık için belirlenen optimum kombinasyon dikkate alınarak her biri için 3 adet doğrulama deneyi yapılmıştır ve deney sonuçları \%95 güven aralığında değerlendirilmiştir. Eş. 3 ve Eş. 4 dikkate alındığında sıcaklık için güven aralığı $(\mathrm{CI})=8.569$ olarak bulunmuştur. Güven aralığının kullanımında, her bir parametre için hesaplanan Taguchi tahmin değeri güven aralığı ile toplanır ve çıkartılır. Doğrulama deneylerinin ortalaması bu iki değer arasında olması istenir. Kesme sıcaklığ için yürütülen 3 adet doğrulama deneylerinin ortalamas1 $44.84{ }^{\circ} \mathrm{C}$ 'dir. Bu durumda sicaklık için; $(44.96-8.569<44.84<(44.96+8.569)=36.391<44.84<$ 53.529 aralığı elde edilmiş ve sicaklık için doğrulama deneyleri güven aralığı içinde gerçekleşmiştir. Bu durumda optimizasyon başarılıdır denilebilir.

Tablo 7'de, Taguchi metodu kullanılarak elde edilen öngörülen değerlerle deney sonuçlarının karşılaştırmasını gösterilmiştir. Tahmin değerlerinin hesaplanmasında Eş.1 ve Eş.2 kullanılmıştır. 
Tahmin edilen değerler ve deneysel değerler birbirine yakın çıkmıştır. Güvenilir istatistiksel analiz için hata değerleri \%20'den az olmalıdır [30].

Tablo 7. Optimize ve rastgele koşulların tahmin değerlerle karşılaştırılması (Comparison of optimized and random conditions with predicted values)

\begin{tabular}{lccc}
\hline \multirow{2}{*}{ Seviyeler } & \multicolumn{3}{c}{ Taguchi metodu } \\
\cline { 2 - 4 } & Deneysel & Tahmin & Hata (\%) \\
\hline $\mathrm{A}_{2} \mathrm{~B}_{2} \mathrm{C}_{2} \mathrm{D}_{1}$ (Optimum) & 44.84 & 44.96 & 0.266 \\
\hline $\mathrm{A}_{2} \mathrm{~B}_{1} \mathrm{C}_{2} \mathrm{D}_{3}$ (Rastgele) & 49.90 & 55.96 & 10.82 \\
\hline $\mathrm{A}_{1} \mathrm{~B}_{3} \mathrm{C}_{3} \mathrm{D}_{3}$ (Rastgele) & 55.30 & 62.14 & 11.01 \\
\hline
\end{tabular}

Tablo 7'de, doğrulama testi sonuçları ile Taguchi metoduyla elde edilen sonuçlar arasındaki hata değerleri \%20'den az olduğu görülmektedir. Bu durumda doğrulama deneyleriyle elde edilen sonuçlar göstermektedir ki, optimizasyon başarılı bir şekilde gerçekleştirilmiştir.

\subsection{Kesme Parametrelerinin Sıcaklık Üzerine Etkisi (Effect of Cutting Parameters on Temperature)}

Deneysel sonuçlara etki eden kesme parametreleri ve bu parametrelerin etkisi üç boyutlu grafiklerle değerlendirilmiştir (Şekil 5). Şekil 4a'da ilerleme oranı ve kesici uçların kesme sıcaklığ1 üzerine etki grafiği gösterilmiştir. Burada ilerleme oranı arttıkça sıcaklığın da arttığı görülmektedir. En düşük sicaklık değeri $0.25 \mathrm{~mm} /$ diş ilerleme oranı ve TiN-TiCN- $\mathrm{Al}_{2} \mathrm{O}_{3}$ kaplamalı kesici uçta olduğu görülmektedir. Bu durum Taguchi optimizasyon değerleri ile örtüşmektedir. Şekil 5a'da en yüksek sıcaklığın ise, ALTiN kaplamalı kesici uç, $0.15 \mathrm{~mm} /$ diş ilerleme oranı ve TiALN kaplamalı kesici uç, $0.35 \mathrm{~mm} /$ diş ilerleme oranlarında olduğu görülmektedir. Ayrıca TiN-TiCN- $\mathrm{Al}_{2} \mathrm{O}_{3}$ kaplamalı kesici ucun bütün ilerleme oranlarında iyi performans göstermiştir.
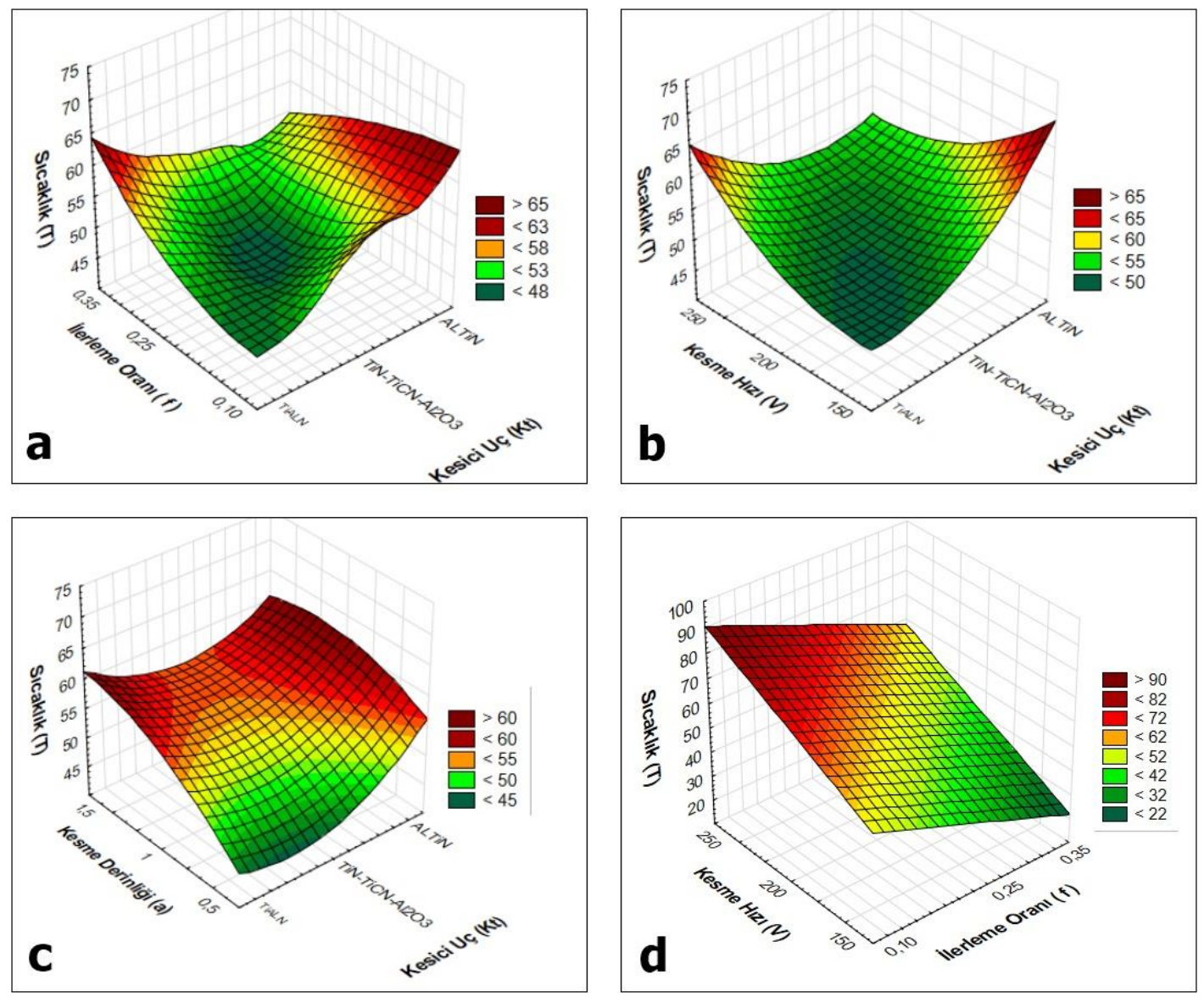

Şekil 5. Kesme parametrelerinin sıcaklık üzerine etkileri (Effects of cutting parameters on temperature) 
Şekil 5b'de kesici uç ve kesme hızının, kesme sıcaklığı üzerine etkileri gösterilmiştir. Burada kesme hızı arttıkça sıcaklığın arttığı görülmektedir. En düşük sıcaklığın TiALN kesici uç ve 150 $\mathrm{mm} /$ dak kesme hızı ile TiN-TiCN-Al $\mathrm{O}_{3}$ kaplamalı kesici uç ve $200 \mathrm{~m} /$ dak kesme hızında olduğu görülmektedir. Bu durum yine Taguchi optimizasyon değerleriyle benzerlik göstermektedir. Şekil 4b'de en yüksek sıcaklığın ALTiN kaplamalı kesici uç ve $150 \mathrm{~m} /$ dak kesmehızı, TiALN kaplamalı kesici uç ve $250 \mathrm{~m} /$ dak kesme hızlarında olduğu görülmektedir. Burada da en iyi performansı TiNTiCN-Al ${ }_{2} \mathrm{O}_{3}$ kaplamalı kesici uç göstermiştir. Şekil 5c'de kesici uç ve kesme derinliğinin sıcaklık üzerine etkileri gösterilmiştir. Burada kesme derinliği arttıkça sıcaklığın arttığı görülmektedir. En düşük kesme sıcaklığının TiALN ve TiN-TiCN-Al ${ }_{2} \mathrm{O}_{3}$ kaplamalı kesici uçlar ve $0.5 \mathrm{~mm}$ kesme derinliğinde olduğu görülmektedir. Bu durum da Taguchi optimizasyon değerleriyle örtüşmektedir. Şekil 4c'de en yüksek sıcaklı değerleri; TiALN kaplamalı kesici uç ve $1.5 \mathrm{~mm}$ kesme derinliği, ALTiN kaplamalı kesici uç ve $0.5 \mathrm{~mm}$ kesme derinliğinde olduğu görülmektedir. Bu grafikten de anlaşılacağı gibi burada da en iyi performansı TiN-TiCN-Al $\mathrm{O}_{3}$ kaplamalı kesici uç göstermiştir. Şekil 5d'de kesme hızı ve ilerleme oranının kesme sıcaklığı üzerine etkileri gösterilmiştir. Burada kesme hızı arttıkça sıcaklığın arttığı, en yüksek sıcaklığın ise $0.10 \mathrm{~mm} /$ diş ilerleme oranı ve 250 $\mathrm{m} /$ dak kesme hızında olduğu görülmektedir. En düşük sıcaklık değeri ise $15 \mathrm{~m} /$ dak kesme hızı ve $0.25 \mathrm{~mm} /$ diş ilerleme oranında olduğu görülmektedir.

TiALN kaplamalar, çok yüksek sertliğe ve sıcaklık direncine sahip olup, yüksek sıcaklıklarda iyi aşınma direnci sunmakta ve takım ömrünü arttırmaktadır [36]. Yapılan çalışmalar dikkate alındığında bu kaplama türü, işlenebilirlik çalışmalarında, düşük takım aşınması ve düşük kesme kuvvetleri sunmaktadır [37, 38]. Diğer taraftan TiN-TiCN-AL $\mathrm{O}_{3}$ kaplamalar çok katmanlı yapıları sayesinde aşınma dirençleri oldukça iyidir. Ancak bu kaplamalarda iyi yüzey kalitesinin elde edilemediği literatürde ifade edilmektedir. $\mathrm{Bu}$ tür kaplamalar daha çok kaba işlemede tercih edilmektedir [39, 40]. Alüminyum-titanyum-nitrür kaplama (AlTiN), alüminyum, titanyum ve azot elementlerinin kimyasal bir bileşimidir. Kaplama kalınlığı 1-4 $\mu \mathrm{m}$ arasındadır. AlTiN kaplamanın özelliği, 1sıya ve oksidasyona karşı çok yüksek direnç göstermesidir. Özellikle talaşlı imalatda, yüksek kesme kuvvetlerinde iyi performans gösterirler [41]. Kesme bölgesindeki artan sıcaklıklar bu kaplama türüne sahip kesici ucta talaş yapışmasını da arttırmaktadır. Literatürde, AlTiN kaplamalı kesici uçlarda paslanmaz çeliklerin frezelenmesi operasyonunda bu kaplamaya sahip kesici uçlarda yapışma görülmüştür. Ayrıca aynı çalışmada, yüksek pürüzlülük değerleri elde edilmiştir. Bu durum takım aşınmasını ve kesme bölgesi sıcaklığını arttıkmaktadır [42]. Literatür incelendiğinde özellikle çeliklerin işlenmesinde kesme hızının artması kesme bölgesi sıcaklığını da arttırdığ 1 ifade edilmektedir $[43,44]$. Yüksek kesme hızlarında, birim zamanda kesici takım ve talaş temas süresi artacağından, sürtünmelerin yükselmesi, dolayısıyla kesme bölgesi sicaklık değerlerinin de artması beklenen bir durumdur [45]. Bu çalışmada literatüre benzer sonuçlar elde edilmiştir. Üç boyutlu grafikler incelendiğinde kesme hızı ile beraber sıcaklığın da arttığ görülmektedir. Talaş kaldırma esnasında ortaya çıkan sıcaklık, kesici takım performansını önemli ölçüde etkilemektedir. Talaş kaldırma esnasında oluşan sıcaklığın büyük bölümü talaş vasıtasıyla kesme bölgesinden uzaklaştırılır literatürde delme işlemlerinde ilerleme oranının artmasıyla kesme sıcaklığının da arttığı belirtilmektedir [46].

\section{SONUÇLAR (CONCLUSIONS)}

$\mathrm{Bu}$ çalışmada GG25 dökme demire uygulanan yüzey frezeleme işlemlerinde, kesme parametrelerinin kesme bölgesi sıcaklığına etkileri araştırılmıştır. Deneysel tasarım için Taguchi metodu kullanılmış olup 27 adet deney yapılmıştır. Çalışmada kesme parametreleri optimize edilmiş ve optimizasyon sonrası, optimize parametreler ile üç adet doğrulama deneyi gerçekleştirilmiştir. Taguchi tahmin değerleri ile deneysel sonuçlar karşılaştırılmıştır. Ayrıca kesme 
parametrelerinin sıcaklık üzerine etkileri üç boyutlu grafiklerle değerlendirilmiştir. Bu çalışmadan elde edilecek sonuçları şu şekilde sıralamak mümkündür;

- Yapılan optimizayon sonucunda, minimum sıcaklık değerleri için deney parametrelerinin optimum kombinasyonu $\mathrm{A}_{2} \mathrm{~B}_{2} \mathrm{C}_{2} \mathrm{D}_{1}\left(\mathrm{~A}_{2}=\right.$ TiN-TiCN- $\mathrm{Al}_{2} \mathrm{O}_{3}$ kaplamalı kesici uç, $\mathrm{B}_{2}=200$ $\mathrm{m} /$ dak kesme hızı, $\mathrm{C}_{2}=0,25 \mathrm{~mm} /$ diş ilerleme oranı ve $\mathrm{D}_{1}=0.5 \mathrm{~mm}$ kesme derinliği) olarak çıkmıştır.

- Optimize parametreler ile yürütülen üç adet doğrulama deneyi ortalaması $\left(44.84{ }^{\circ} \mathrm{C}\right)$, deney sonuçları ortalamasının $\left(54.659^{\circ} \mathrm{C}\right)$ altında gerçekleşmiştir.

- Varyans analizi sonuçları değerlendirildiğinde sıcaklığa etki eden en etkili parametre \%26.51 ile kesme derinliği olmuştur. İkinci olarak en etkili parametre, \% 6.15 ile kesici uç olmuştur.

- Taguchi metodu kullanılarak hesaplanan tahmin değeri $\left(44.96{ }^{\circ} \mathrm{C}\right)$ deney sonuçları ortalamasının altında çıkmıştır.

- Optimum parametreleri ile rastgele seçilen parametreler ile yürütülen deneylerden elde edilen sonuçlar Taguchi tahmin değerleri ile karşılaştırıldığında hata değerleri \%2'nin altında çıkmıştır.

- Üç boyutlu grafikler değerlendirildiğinde minimum sıcaklık için en uygun kesi uç kaplaması TiN-TiCN-Al ${ }_{2} \mathrm{O}_{3}$ kaplamalı kesici uç olup bu durum Taguchi optimize parametreler ile benzerlik göstermiştir. Bu durum bu kaplama türünün çok katmanlı olmasından dolayı yüksek aşınma direncine atfedilmektedir.

- AlTiN kaplamaya sahip kesici uçta yüksek sıcaklıklar elde edilmiştir.

- Literatür bilgileri ve bu çalışma genel olarak değerlendirildiğinde kesici uç kaplama türü kesme bölgesi sıcaklığına doğrudan etkilidir.

- Ayrıca kesme hızı arttıkça kesme bölgesi sıcaklığının da arttığı görülmüştür. Bu durum literatürle örtüşmektedir.

- GG25 malzemeye uygulanacak yüzey frezeleme işlemlerinde, kesme hızı ve ilerleme oranı takım üretici katalog bilgilerine bağlı kalınarak seçilmelidir. Kesici uç ise, TiN-TiCN- $\mathrm{Al}_{2} \mathrm{O}_{3}$ kaplamalı seçilmesi tavsiye edilmektedir.

- TiN-TiCN-Al $\mathrm{O}_{2}$ kaplamalı kesici uç, yüksek ilerleme de bile düşük kesme sıcaklığı için pozitif etki göstermiştir.

- Kesme parametrelerinin bireysel etkileri dikkate alındığında en etkili faktör olarak kesici uç olmuştur. Bu durum kesici uç kaplama tiplerine atfedilmektedir.

Bu çalışmada deney sayısının azaltılması ve deneysel tasarım için Taguchi metodu kullanılmış, bu sayede zamandan ve işleme maliyetlerinden tasarruf sağlanmıştır. Tam tasarım olarak 81 deney yerine 27 adet deney yapılmıştır. Deneysel ve Taguchi sonuçları değerlendirildiğinde elde edilen sonuçlar uygulanabilir ve tatmin edicidir. Dolayısıyla Taguchi metodu bu çalışmaya başarılı bir şekilde uygulanmıştır. Sonuçlar genel olarak değerlendirildiğinde, özellikle TiAlN ve AlTiN kaplamalı kesici uçlarda ilerleme oranının artmasıyla beraber kesme sıcaklığının da arttığı görülmüştür. Gerek literatür, gerekse bu çalışma sonuçları değerlendirildiğinde, GG25 malzemenin yüzey frezeleme operasyonlarında kesme sıcaklığının değişimi birincil olarak kullanılan kesici takım kaplama türüne bağlıdır denilebilir. Sonraki çalışmalarda GG25 dökme demirin yüzey frezeleme işlemlerinde, takım aşınması ve yüzey pürüzlülüğü değerleri aynı ortogonal dizi kullanılarak ölçülebilir ve deneysel sonuçlar optimize edilebilir. 


\section{KAYNAKLAR (REFERENCES)}

1. Ö. Çelik, Küresel Grafitli dökme demirlerin aşınma davranışları, Yüksek Lisans Tezi, İstanbul Üniversitesi Fen Bilimleri Enstitüsü, İstanbul, Türkiye, 2001.

2. V.S.R. Murthy, S. Kishore Seshan, Characteristics of compacted Graphite Cast Iron, Transactions of the American Foundrymen's Society, 92:373-380, 1984.

3. R.T. Coelho, A.F. Souza, A.R. Roger, A.M.Y. Rigatti, A.A. Riberio, Mechanistic approach to predict real machining time for milling free-form geometries applying high feed rate, International Journal of Advanced Manufacturing Technology, 46: 1103-1111, 2010.

4. C.H. Hsu, M.L. Chen, C.J. Hu, Microstructure and mechanical properties of $4 \%$ cobalt and nickel alloyed ductile irons, Materials Science and Engineering A, 444: 339-346, 2007.

5. U. Şeker, İ. Çiftçi, H. Hasirci, The effect of alloying elements on surface roughness and cutting forces during machining of ductile iron, Materials and Design, 24: 47-51, 2003.

6. I. Ucun, K. Aslantas, The performance of ceramic and cermet cutting tools for the machining of austempered ductile iron, International Journal of Advanced Manufacturing Technology, 41: 642-650, 2009.

7. A.K. Ghani, I.A. Choudhury, Husni, Study of tool life, surface roughness and vibration in machining nodular cast iron with seramic tool Journal of Materials Processing Technology 127: 17-22, 2002.

8. F. Klocke, C. Klöpper, D. Lung, C. Essig, Fundamental wear mechanisms when machining austempered ductile iron (ADI), Annals of the CIRP., 56(1): 73-76, 2007.

9. M.C. Cakir, A. Bayram, Y. Isik, B. Salar, The effects of austempering temperature and time onto the machinability of austempered ductile iron, Materials Science and Engineering A, 407: 147-153, 2005.

10. M. Çetin, F. Gül, Östemperlenmiş küresel grafitli dökme demirin abrasiv aşınma davranışına östemperleme işleminde soğutmanın etkisi, Gazi Üniv. Müh. Mim. Fak. Der., 21(2): 359-366, 2006.

11. O.J. Moncada, R.H. Spicacci, J.A. Sikora, Machinability of austempered ductile iron, AFS Trans, 106: 39-45, 1998.

12. M.C. Çakır, Modern Talaşlı İmalatın Esasları. Uludağ Üniversitesi Güçlendirme Vakfı, Bursa, 140: 155-239, 1999.

13. R.O. Marwanga, R.C. Voigt, P.H. Cohen, Influence of graphite morphology and matrix structure on chip formation during machining of continuously cast ductile irons, AFS Transactions, 108: 651, 2000.

14. A. Yardımeden, M. Aksoy, A. İnan, Lamel grafitli dökme demirlerin işlenmesinde kale mile parça arasında meydana gelen gerilime, işleme şartları ve malzeme yapısının etkisi, 11. Uluslararası Makina Tasarım ve İmalat Kongresi, 13-15 Ekim, 2004, Antalya.

15. A. Kaçal, B. Çelik, Ş. Sertsöz, GGG70 sfero dökme demirin frezelenmesinde yüzey pürüzlülüğ̈̈ ve takım aşınmasının incelenmesi, IMCOFE 2019, 24-26 Nisan, 2019, Antalya.

16. Y. Kahraman, G. Uzun, İ. Korkut, Vermiküler grafitli dökme demirlerin frezelenmesinde östemperleme sicaklığı ve süresinin yüzey pürüzlülügüne etkisi, 6. Ulusal Talaşlı İmalat Sempozyumu (UTíS 2015), 5-7 Kasım, 2015, İstanbul.

17. R. Çakıroğlu, G. Uzun, Yüksek ilerleme ile frezeleme işlemi esnasında oluşan kesme kuvvetinin ve iş parçası yüzey pürüzlülüğünün Yapay Sinir Ağları ile modellenmesi, Gazi Mühendislik Bilimleri Dergisi, 7(1): 58-66, 2021.

18. Y. Aşkun, H. Hasırcı, U. Şeker, Ni ve $\mathrm{Cu}$ ile alaşımlandırılmış küresel grafitli dökme demirlerin işlenebilirliliğinin kesme kuvvetleri ve yüzey kaliteleri açısından değerlendirilmesi, Pamukkale Üniversitesi Mühendislik Fakültesi, Mühendislik Bilimleri Dergisi, 9(2): 191-199, 2003.

19. B. Avishan, S. Yazdani, D. Jalali Vahid, The influence of depth of cut on the machinability of an alloyed austempered ductile iron, Materials Science and Engineering A, 523: 93-98, 2009.

20. A. E. Da Silva, I.N. Rabelo de Melo, I.P. Pinheiro, L.R. Da Silva, Characterisation and machinability of high chromium hardened white cast iron with and without the addition of niobium, Wear, 460-461: 116, 2020.

21. D. Eraslan, A. Balcı, B. Çetin, N. Uçak, A. Çiçek, O. D. Yılmaz, K. Davut, Machinability evaluations of austempered ductile iron and cast steel with similar mechanical properties under eco-friendly milling conditions, Journal of Materials Reserch and Technology, 11: 1443-1456, 2021. 
22. J. Lu, Z. Zhang, X. Yuan, J. Ma, S. Hu, B. Xue, X. Liao, Effect of machining parameters on surface roughness for compacted graphite cast iron by analyzing covariance function of Gaussian process regression, Measurement, 157: 1-11, 2020.

23. L.R.R. da Silva, F.C.R. Souza, W.L. Guesser, M.J. Jackson, A.R. Machado, Critical assessment of compacted graphite cast iron machinability in the milling process, Journal of Manufacturing Processes, 56: 63-74, 2020.

24. F.Taylan, Sert malzemelerin frezelenmesinde takım aşınma davranışlarının belirlenmesi, Doktora Tezi, Süleymen Demirel Üniversitesi, Isparta, Türkiye, 2009.

25. United Cast Bar Unibar 250 Continuously Cast Iron, EN-1561-GJL-250 GG25, http://www.matweb.com/search/DataSheet.aspx?MatGUID=e9567779213346e28649f59333549e48\&ck $\mathrm{ck}=1,11.11 .2021$.

26. A. M. Pınar, A. Güllü, A. (2010). Sayısal denetimli hidrolik pozisyonlama sisteminin Taguchı metodu ile optimizasyonu. Gazi Üniv. Müh. Mim. Fak. Der, 25(1): 93-100, 2010.

27. M., Savaşkan, Y. Taptık, M. Ürgen, Performance optimization of drill bits using design of experiments. Journal of ITU, 3(6): 117-128, 2004.

28. WIDIA Cutting tool company, Advances catalog, 2020.

29. WIDIA Cutting tool company, Master Catalog, 2017

30. F. Kara, Optimization of surface roughness in finish milling of AISI P20+S plastic-mold steel, Materiali in tehnologije/Materials and technology, 52(2): 195-200, 2018.

31. G. Samtaş, S. Korucu, Kriyojenik işlem görmüş EN AW 5754 (AlMg3) alüminyum alaşımının frezelenmesinde yüzey pürüzlülüğü için kesme parametrelerinin optimizasyonu, Politeknik Dergisi, 22 (3): 665-673, 2019.

32. F. Kara, B. Öztürk, Comparison and optimization of PVD and CVD method on surface roughness and flank wear in hard-machining of DIN 1.2738 mold steel, Sensor Review, 39 (1): 24-33, 2019.

33. T. Kivak, Optimization of surface roughness and flank wear using the Taguchi method in milling of Hadfield steel with PVD and CVD coated inserts, Measurement, 50: 19-28, 2014.

34. G. Samtaş, Optimisation of cutting parameters during the face milling of AA5083-H111 with coated and uncoated inserts using Taguchi method, Int. J. Machining and Machinability of Materials, 17 (3/4): 211-232, 2015.

35. G. Samtaş, S. Korucu, Temperlenmiş Alüminyum 5754 Alaşımının Frezelenmesinde Kesme Parametrelerinin Taguchi Metodu Kullanılarak Optimizasyonu, Düzce Üniversitesi Bilim ve Teknoloji Dergisi, 7(1): 45-60, 2019.

36. Alüminyum Titanyum Nitrür (AlTiN/TiAlN) Kaplama, https://www.titanit.com.tr/pvd-kaplama/zafirplus/, 15.11.2021.

37. A. S. Kumar, A. R. Durai, T. Sornakumar, The effect of tool wear on tool life of alumina-based ceramic cutting tools while machining hardened martensitic stainless steel, Journal of Materials Processing Technology, 151-156, 2006.

38. Ö. Tekaslan, N. Gerger, U. Şeker, AISI 304 östenitik paslanmaz çeliklerin farklı kesme parametreleri ile tornalama işleminden sonra oluşan kalıcı gerilmelerin araştırılması, Gazi Üniv. Mühendislik-Mimarlık Fakültesi Dergisi, 443-452, 2009.

39. R.P. Martinho, F.J.G. Silva, C. Martins, H. Lopes, Comparative study of PVD and CVD cutting tools performance in milling of duplex stainless steel. International Journal of Advanced Manufacturing Technology, 102(5-8): 2423-2439, 2019.

40. N. Szczotkarz, R. W. Maruda, D. Dębowski, K. Leksycki, S. Wojciechowski, N. Khanna, G. M. Królczyk, Formation of surface topography during turning of AISI 1045 steel considering the type of cutting edge coating, Advances in Science and Technology Research Journal, 15(4): 253-266, 2021.

41. General information about AlTiN coating, https://ruko.de/en/blog/altin-the-aluminium-titanium-nitritecoating, 15.11.2021.

42. E. Kuram, AISI 304 paslanmaz çeliğinin frezelenmesinde farklı kaplama malzemelerinin takım aşınmasına, kesme kuvvetlerine ve yüzey pürüzlülüğüne etkileri, Politeknik Dergisi, 19(4): 433-443, 2016.

43. A. Aslan, Tornalama parametrelerinin kesme sıcaklığı ve krater aşınması üzerine etkilerinin deneysel olarak araştırılması, Türk Doğa ve Fen Dergisi, 10(1): 109-118, 2021. 
44. U. Karagüzel, Ti6A14V alaşımının talaşlı imalatı sırasında termal kamera ile sıcaklık ölçümü ve sonlu elemanlarla modellenmesi, Mühendislik Bilimleri ve Tasarım Dergisi, 7(2): 265-271, 2019.

45. U. ÇAydaş, O. Kuncan, M. Çelik, AISI 52100 rulman çeliğinin işlenebilirliğinin yüzey pürüzlülüğü, takım ömrü ve sıcaklık kriterine göre araştırılması, Politeknik dergisi, 20(2): 409-417, 2017.

46. B. Yılmaz, G. Uzun, A. Güllü, Ti6Al4V malzemeye uygulanan delme işleminde kesme parametrelerinin itme kuvveti, kesme momenti ve kesme sıcaklığına etkisi, İmalat Teknolojileri ve Uygulamaları, 1(3): $1-8,2020$. 